ด

columns and how they should be working and, instead of introducing flexibility, enforce rigidity. They lose person-centred holistic care by replacing skilled clinicians with tick-box policies and procedures (Drife, 2006) for people working beyond their competencies.

DRIFE, J. O. (2006) The history of box ticking. BMJ, 333, 557.

GENERAL MEDICAL COUNCIL (2006) Management for Doctors. General Medical Council (http:// www.gmc-uk.org/guidance/current/library/ management_for_doctors.pdf)

SAINSBURY CENTRE FOR MENTAL HEALTH (2003)

Money for Mental Health. A Review of Public Spending on Mental Health Care. Sainsbury Centre for Mental Health (http://www.scmh.org.uk/ 80256FBD004F3555/wWeb/fIKHAL6TJLJ6/\$file/ scmh_money_for_mental_health.pdf).

Susan Mary Benbow Professor of Mental Health and Ageing Centre for Ageing and Mental Health Staffordshire University, Blackheath Lane, Stafford ST18 0AD, email: drsmbenbow@aol.com

doi: $10.1192 / p b .32 .5 .195 b$

\section{Assessment of mental capacity: who can do it, or who should do it?}

I was interested to read about the discrepancy in the number of capacity assessments carried out by doctors on general adult and old age psychiatry wards (Singhal et al, Psychiatric Bulletin, January 2008, 32, 17-19). Although the authors gave no explanation, the result could be because in-patients on the general adult wards, who probably lacked capacity, were more likely to be detained under the Mental Health Act and therefore fell outside the Bournewood gap.

This result does however support my belief that doctors on general adult psychiatry wards do not assess their patient's capacity (to consent to treatment) often enough.

I took part in a survey (Hill et al, 2006) in which consultant and trainee psychiatrists were asked, 'What are the key elements in the assessment of a patient's capacity?' Over a third of the 95 participants could only identify two or less of the five points in testing decision-making capacity (Department of Health, 2005; Re C, 1994). This suggested an inadequate level of knowledge and I believe that as doctors we could become even more de-skilled, should we rely entirely on our nursing colleagues to fulfil this role in future.

The authors make the point that 'Appropriately trained mental health nursing staff can undertake this assessment.' I am sure they can, but should they?
I believe it is appropriate that as prescribing doctors, we should be assessing our patient's capacity to consent to the proposed treatment, and not merely delegate these duties to other healthcare professionals. This makes sense from an ethical and medico-legal perspective.

\section{DEPARTMENT OF HEALTH (2005) Mental Capacity} Act 2005. Department of Health.

HILL, S. A. MATHER, G. I \& JAMES, A. J. (2006) Assessing decision-making capacity: a survey of psychiatrists' knowledge. Medicine Science and the Law, 46, 66-68.

Re C (Adult: Refusal of Medical Treatment) [1994] 1 AllER 819

Schalk du Toit Specialty Registrar Year 4 in General Adult Psychiatry, National Health Service Grampian, Royal Cornhill Hospital, 26 Cornhill Road, Aberdeen AB25 2ZH, email: s_dutoit@doctors.org.uk

doi: 10.1192/pb.32.5.196

\section{Re-examination of forensic psychiatry needs a proper examination of alternatives}

Turner \& Salter's re-examination of the relationship between forensic and general psychiatry was provocative and rehearsed the criticisms from generalists towards their forensic colleagues (Psychiatric Bulletin, January 2008, 32, 2-6). No doubt it is important for forensic psychiatrists to consider external views in reflecting on their own practice. However, I feel it necessary to highlight the fallacy of simply adopting the US system, as was suggested by the authors. Their approach of effectively separating the treatment of offenders with mental disorders from the contribution of psychiatry to the court room brings with it serious ethical problems which should not be overlooked. One line of thinking, as advanced by Stone (1984), argues that clinicians should not act as expert witnesses as they cannot help but use their therapeutic skills at interview which may induce disclosures used by courts for nonmedical purposes. However, this raises the unedifying prospect of participants in the legal process unused to delivering psychiatric treatment being responsible for advising the court on mental health disposals. This does not seem to me in the interests of the justice or the best way to ensure treatment needs are met. An alternative view expressed by Appelbaum (1997) argues that psychiatric testimony falls outside traditional medical practice and therefore is not subject to traditional medical ethics, meaning that psychiatrists need not feel bound by medical ethics when acting as expert witnesses. However, it is difficult to see how a trained psychiatrist would not, unwittingly or otherwise, use their specialist interviewing skills in obtaining evidence from a defendant. For this reason they should be bound, at least in part, by the ethics of their profession.

In my view, the most appropriate approach to be taken in the UK was explained by O'Grady (2002), who incidentally provided the response to Turner \& Salter's article (2008). O'Grady argues that forensic psychiatrists should adhere to both justice ethics (truthfulness, respect for autonomy and respect for the human rights of others) as well as medical ethics (beneficence and non-maleficence). This type of theory of 'mixed duties' was approved by the Royal College of Psychiatrists (2004). It encourages forensic psychiatrists to be highly sensitive to the ethical dilemmas inherent in their sub-specialty. I acknowledge the brief nature of Turner \& Salter's article, but feel their suggestion that the problems they perceive could be resolved simply by adopting the US practice is overly simplistic and should have been accompanied by a description of the limitations of this approach.

APPELBAUM, P. S. (1997) A theory of ethics for forensic psychiatry. Journal of the American Academy of Psychiatry and the Law, 25, 233-247.

ROYAL COLLEGE OF PSYCHIATRISTS (2004) The Psychiatrist, Courts and Sentencing: the Impact of Extended Sentencing on the Ethical Framework of Forensic Psychiatry. College Report CR 129 (http:// www.rcpsych.ac.uk/publications/collegereports/ cr/cr129.aspx).

O'GRADY, J. (2002) Psychiatric evidence and sentencing: ethical dilemmas. Criminal Behaviour and Mental Health, 12, 179-184.

O'GRADY, J. (2008) Time to talk. Commentary on... Forensic psychiatry and general psychiatry. Psychiatric Bulletin, 32, 6-7.

STONE, A. A. (1984) Ethical boundaries of forensic psychiatry: a view from the ivory tower. Bulletin of the American Academy of Psychiatry and Law, 12, 209-219.

Andy Bickle Specialist Registrar in Forensic Psychiatry, East Midlands Centre for Forensic Menta Health, Leicester, email: Andrew.Bickle@nottshc. nhs.uk

doi: $10.1192 / p b .32 .5 .196 a$

\section{Does hyoscine need to be 'legally' prescribed?}

A recent visit to the Wickham Unit (a lowsecure rehabilitation unit) at Blackberry Hill Hospital, Bristol, by the Mental Health Act Commission raised a controversial issue regarding the legal prescribing of medication for individuals who are detained under the Mental Health Act. There was a case of a patient who had consented to treatment and had a Form 38 completed in accordance with Section 